Article

\title{
Uptake of As(V) from Groundwater Using Fe-Mn Oxides Modified Kaolin Clay: Physicochemical Characterization and Adsorption Data Modeling
}

\author{
Rabelani Mudzielwana ${ }^{1, *(\mathbb{C})}$, Mugera Wilson Gitari ${ }^{1}\left(\mathbb{D}\right.$ and Patrick Ndungu ${ }^{2}(\mathbb{D}$ \\ 1 Environmental Remediation and Nanoscience Research Group, Department of Ecology and Resource \\ Management, University of Venda, Thohoyandou 0950, South Africa; mugera.gitari@univen.ac.za \\ 2 Department of Applied Chemistry, University of Johannesburg, Doornfontein, \\ Johanessburg 2028, South Africa; pndungu@uj.ac.za \\ * Correspondence: 11600806@mvula.univen.ac.za
}

Received: 18 March 2019; Accepted: 23 April 2019; Published: 14 June 2019

\begin{abstract}
The present study evaluated the effectiveness of Fe-Mn modified kaolin clay in the uptake of $\mathrm{As}(\mathrm{V})$ from the solution. The elemental composition was characterized using $\mathrm{X}$-ray fluorescence (XRF), while the surface morphology was characterized using Scanning Electron Microscopy (SEM). The surface area, pore diameter, and pore volume were determined using Brunauer, Emmett, and Teller (BET) and Barrett-Joyner-Halenda (BJH) techniques. The efficiency of the Arsenic removal of the adsorbent was evaluated using batch experiments. The results showed that the percentage of $\mathrm{As}(\mathrm{V})$ removal is optimum at acidic $\mathrm{pH}$ and decreased as the solution $\mathrm{pH}$ becomes more alkaline. The adsorption kinetics data fitted better to pseudo-second-order compared to the pseudo-first-order of reaction kinetics. The adsorption isotherm data fitted to the Langmuir isotherm model showing a maximum adsorption capacity of $2.44 \mathrm{mg} / \mathrm{g}$, adsorbate concentration range of $1-30 \mathrm{mg} / \mathrm{L}$, and adsorbent dosage of $0.4 \mathrm{~g} / 100 \mathrm{~mL}$. The value of $\Delta \mathrm{G}^{\circ}$ of the thermodynamic parameter was found to be negative, while $\Delta \mathrm{H}^{\circ}$ and $\Delta \mathrm{S}^{\circ}$ were found to be positive. For the regeneration-reuse study, the percentage of removal was found to be $>85 \%$ after the sixth cycle of reuse. The results obtained from this study showed that Fe-Mn modified kaolin (FMK) is suitable for use in the uptake of $\mathrm{As}(\mathrm{V})$ from groundwater.
\end{abstract}

Keywords: arsenic; adsorption; kinetics; isotherms; thermodynamics and regeneration

\section{Introduction}

The abstraction of groundwater is the most common source of water for domestic purposes in the majority of rural communities around the world, especially in arid and semi-arid regions where rainfall is scarce [1]. However, the presence of elements, such as arsenic, in groundwater is a major concern from the health and environmental point of view due to its negative implications on human health. Prolonged exposure to arsenic through drinking water is associated with various types of cancer, cardiovascular diseases, skin thickening, and neurological diseases [2,3]. It is estimated that 200 million people worldwide are suffering from arsenic-related diseases [4]. In 1993, the World Health Organization (WHO) had reduced the permissible limit from $50 \mu \mathrm{g} / \mathrm{L}$ to $10 \mu \mathrm{g} / \mathrm{L}$ with the aim of controlling arsenic-related diseases [5]. Furthermore, the WHO recommended the installation of arsenic removal systems in areas where groundwater contains arsenic concentration beyond $10 \mu \mathrm{g} / \mathrm{L}$.

Available arsenic removal technologies, such as precipitation and coagulation, oxidation, ion exchange, reverse osmosis, and adsorption, were reviewed by Sarkar and Paul [4]. Amongst these technologies, adsorption is the most preferred one because of its sustainability and flexibility in terms of cost. Materials, such as clay soils [6], nanostructured Fe-Ti-Mn composite [7], chitosan-modified 
vermiculite [8], alum sludge [9], and Fe-Mn binary oxides [10], have been reported for their efficiency in arsenic removal. Some of these reported materials operate at a narrow $\mathrm{pH}$ range and have a limited life span. Furthermore, their performance is affected by the presence of co-existing ions.

Clay and clay minerals have attracted vast interest for application in water decontamination due to their excellent properties, such as good mechanical and chemical stability, higher cation/anion exchange, and higher surface area [11]. Nonetheless, clays are abundantly available in the natural environment at little or no cost. Adding to their advantages, clays can be modified to enhance their adsorption capacity towards anionic and cationic species. Several authors have reported enhanced adsorption capacity of modified clays towards arsenic. This includes FeOOH modified clays [12], Fe and cetyltrimethylammonium bromide (CTMAB) modified montmorillonite [13], and iron-oxide modified sericite alginate [14]. Fe and $\mathrm{Mn}$ are closely related elements in terms of chemical properties that occur together in the soils and sediments. Furthermore, they are known to have a higher affinity towards the adsorption of arsenic [10]. The present study focuses on the preparation of low-cost adsorbent for $\mathrm{As}(\mathrm{V})$ by intercalating $\mathrm{Fe}^{3+}$ and $\mathrm{Mn}^{2+}$ oxides onto kaolin clay interlayers. The synthesized adsorbent was characterized for its chemical composition, morphology, surface area, and pore distribution using standard laboratory techniques. The adsorbent's affinity towards $\mathrm{As}(\mathrm{V})$ removal was evaluated using batch experiments. Adsorption kinetics and isotherms models were used to elucidate the adsorption mechanisms.

\section{Methodology}

\subsection{Materials}

Naturally available kaolin clay mineral was collected from Dzamba Village, Limpopo Province, South Africa. All analytical grade chemical reagents were purchased from Rochelle Chemicals \& Lab Equipment CC, South Africa Ltd, and they were used without further purification. Stock solutions containing $1000 \mathrm{mg} / \mathrm{L} \mathrm{As}(\mathrm{V})$ was prepared by dissolving $0.416 \mathrm{~g} \mathrm{HAsNa} \mathrm{O}_{4} \cdot 7 \mathrm{H}_{2} \mathrm{O}$ in a $100 \mathrm{~mL}$ flask using Milli-Q water $(18.2 \mathrm{M} \Omega / \mathrm{cm})$. Working solutions were prepared by appropriate dilutions.

\subsection{Synthesis of the Adsorbent}

To synthesize $\mathrm{Fe}^{3+}-\mathrm{Mn}^{2+}$ binary oxide, solutions containing $0.25 \mathrm{M} \mathrm{Fe}^{3+}$ and $0.25 \mathrm{M} \mathrm{Mn}^{2+}$ were prepared by dissolving appropriate amounts of $\mathrm{FeCl}_{3}$ and $\mathrm{MnCl}_{2} \cdot 4 \mathrm{H}_{2} \mathrm{O}$ salts into $250 \mathrm{~mL}$ volumetric flasks. Thereafter, $\mathrm{Fe}^{3+}$ and $\mathrm{Mn}^{2+}$ solutions were mixed in a ratio of 3:1 in $250 \mathrm{~mL}$ plastic bottle. Thereafter, $1 \mathrm{~g}$ of raw kaolin clay was added onto the solution, and mixtures were agitated for $10 \mathrm{~min}$ to ensure proper soaking. After soaking, solution $\mathrm{pH}$ was adjusted to 8.5 through drop-wise addition of $2 \mathrm{M} \mathrm{NaOH}$ to precipitate $\mathrm{Fe}^{3+}$ and $\mathrm{Mn}^{2+}$ into their respective oxides. Mixtures were agitated further for $60 \mathrm{~min}$ on a Table shaker at $250 \mathrm{rpm}$ and then aged for $62 \mathrm{~h}$. Thereafter, the mixture was centrifuged at $3000 \mathrm{rpm}$. Residues were washed with an excess of Milli-Q water to remove excess supernatants till the $\mathrm{pH}$ was close to neutral and then oven dried for $12 \mathrm{~h}$ at $110^{\circ} \mathrm{C}$. The modified clay was then milled to pass through $250 \mu \mathrm{m}$ sieve and then stored in a zip lock plastic bag. This procedure was repeated until $50 \mathrm{~g}$ of the adsorbent was generated. This material was then designated FMK.

\subsection{Characterization}

The elemental compositions of the adsorbent were evaluated using Bruker S1 titan handheld X-ray fluorescence (XRF, S1 titan 600, Bruker, Berlin, Germany). Loss on Ignition (LOI) was determined by calcining the material at a temperature of $850{ }^{\circ} \mathrm{C}$. Surface area and pore distribution were determined using Brunauer, Emmett, and Teller (BET) (Micromeritics Gemini 2375, Norcross, GA, USA) and Barrett-Joyner-Halenda (BJH) (micromeritics ASAP 2020, Norcross, GA, USA) techniques. The morphology was determined using scanning electron microscopy (SEM) (Leo1450 SEM, Voltage $10 \mathrm{kV}$, working distance $14 \mathrm{~mm}$, Ramsey, NJ, USA). 


\subsection{Arsenic Removal Experiments}

The efficiency of FMK towards As(V) removal was evaluated using batch experiments. Parameters evaluated include contact time, adsorbate concentration, and the $\mathrm{pH}$ of the initial solution. To evaluate the effect of contact time, $100 \mathrm{~mL}$ solution containing $5 \mathrm{mg} / \mathrm{L} \mathrm{As}(\mathrm{V})$ was pipetted into $250 \mathrm{~mL}$ plastic bottle and $0.1 \mathrm{~g}$ of the modified clay was added. The contact time was varied from 10 to $120 \mathrm{~min}$. The effect of initial concentration was evaluated at 298,303 , and $323 \mathrm{~K}$ by varying initial concentration from 1 to $30 \mathrm{mg} / \mathrm{L}$. To evaluate the effect of $\mathrm{pH}$, the $\mathrm{pH}$ of the initial solution was adjusted from 2 to 12 using $0.1 \mathrm{M} \mathrm{NaOH}$ and $0.1 \mathrm{M} \mathrm{HCl}$. After agitation, the samples were filtered using a $0.45 \mu \mathrm{m}$ pore filter membrane using a vacuum pump. The effect of co-existing anions was carried out in the presence of $5 \mathrm{mg} / \mathrm{L}$ of $\mathrm{Cl}^{-}, \mathrm{F}^{-}, \mathrm{NO}_{3}{ }^{-}, \mathrm{CO}_{3}{ }^{2-}, \mathrm{SO}_{4}{ }^{2-}$ using ad adsorbent dosage of $0.4 \mathrm{~g} / 100 \mathrm{~mL}$. The $\mathrm{pH}$ of the solution was measured using JENWAY $3510 \mathrm{pH}$ meter (Lasec, Johannesburg, South Africa). The residual As(V) concentration was analyzed using ScTRACE Gold electrode attached to Metrohm 884 professional VA polarography. A composite solution containing $1 \mathrm{~mol} / \mathrm{L}$ sulfamic acid, $0.5 \mathrm{~mol} / \mathrm{L}$ citric acid, and $0.45 \mathrm{~mol} / \mathrm{L} \mathrm{KCl}$ was used as an electrolyte. For total As concentration, $\mathrm{KMnO}_{4}$ was added as an oxidizing agent. All experiments were carried out in triplicate, and the mean values were reported. Equations (1) and (2) were used to compute the percentage removal and the adsorption capacity, respectively.

$$
\begin{gathered}
\text { \% removal }=\left(\frac{C_{i}-C_{e}}{C_{i}}\right) \times 100 \\
q_{e}=\left(\frac{C_{i}-C_{e}}{m}\right) \times v
\end{gathered}
$$

where $C_{i}$ and $C_{e}$ represent the initial and equilibrium $A s(I I I)$ concentration $(\mathrm{mg} / \mathrm{L})$, respectively, and $\mathrm{m}$ represents the mass of the dry adsorbent $(\mathrm{g})$. $\mathrm{V}$ is the volume $(L)$, and $\mathrm{q}_{\mathrm{e}}$ is the adsorption capacity $(\mathrm{mg} / \mathrm{g})$.

\subsection{Reusability of the Adsorbent}

To evaluate reuse potential of the adsorbent, a total of 6 regeneration-reuse cycles were carried out using $0.1 \mathrm{M} \mathrm{K}_{2} \mathrm{SO}_{4}$ as the regenerating eluent. For the adsorption test, $100 \mathrm{~mL}$ of $5 \mathrm{mg} / \mathrm{L} \mathrm{As}(\mathrm{V})$ solution was pipetted into $250 \mathrm{~mL}$ plastic bottle and $0.4 \mathrm{~g}$ of adsorbent was added and agitated for $60 \mathrm{~min}$ at $250 \mathrm{rpm}$. After agitation, the samples were filtered through $0.45 \mu \mathrm{m}$ filter membranes and the residual $\mathrm{As}(\mathrm{V})$ concentration was measured. For regeneration, dried spent sorbent was added onto $100 \mathrm{~mL}$ of $0.1 \mathrm{M} \mathrm{K}_{2} \mathrm{SO}_{4}$ solution and agitated for $30 \mathrm{~min}$. Thereafter, residues were oven dried at $105^{\circ} \mathrm{C}$ and pulverized to pass through $250 \mu \mathrm{m}$ sieve. The regenerated adsorbent was then reused for $\mathrm{As}(\mathrm{V})$ adsorption. This process was repeated up to six times.

\section{Results and Discussion}

\subsection{Adsorbent Characterization}

Table 1 presents the elemental composition of raw and modified kaolin clay. The analysis revealed that $\mathrm{SiO}_{2}$ and $\mathrm{Al}_{2} \mathrm{O}_{3}$ are the major chemical oxides of raw kaolin (RK) averaging 56.06 and $22.05 \%$, respectively. $\mathrm{Fe}_{2} \mathrm{O}_{3}$ was observed as one of the minor oxides averaging $3.88 \%$, while $\mathrm{MnO}$ was observed as a trace oxide ( $0.01 \%)$. After modification, the percentage composition of $\mathrm{SiO}_{2}$ and $\mathrm{Al}_{2} \mathrm{O}_{3}$ decreased to 39.36 and $10.08 \%$, respectively. Conversely, the percentage composition of $\mathrm{Fe}_{2} \mathrm{O}_{3}$ and $\mathrm{MnO}$ increased to 16.66 and $4.02 \%$, respectively. The results suggest that $\mathrm{Fe}^{3+}$ and $\mathrm{Mn}^{2+}$ oxides were successfully intercalated onto the clay interlayers. Furthermore, $\mathrm{Na}_{2} \mathrm{O}$ content increased from 2.3 to 4.14 after modification. This could be the results of $\mathrm{NaOH}$ used during modification. The percentage composition of $\mathrm{MgO}, \mathrm{CaO}$, and $\mathrm{K}_{2} \mathrm{O}$ also decreased after modification. The decrease in LOI could be attributed to the reduction in organic matter content during clay modification. 
Table 1. Chemical composition of raw kaolin (RK) and FMK.

\begin{tabular}{ccccccccccc}
\hline Oxides (\%w/w) & $\mathrm{SiO}_{2}$ & $\mathrm{Al}_{2} \mathrm{O}_{3}$ & $\mathrm{Fe}_{2} \mathrm{O}_{3}$ & $\mathrm{MnO}$ & $\mathrm{Na}_{2} \mathrm{O}$ & $\mathrm{MgO}$ & $\mathrm{CaO}$ & $\mathbf{K}_{\mathbf{2}} \mathrm{O}$ & $\mathrm{TiO}_{2}$ & $\mathrm{LOI}$ \\
\hline $\mathrm{RK}$ & 56.06 & 22.05 & 3.88 & 0.01 & 2.3 & 0.57 & 0.95 & 0.16 & 1.76 & 11.2 \\
\hline $\mathrm{FMK}$ & 45.39 & 15.08 & 16.66 & 6.02 & 4.14 & $\mathrm{LOD}$ & 0.55 & 0.13 & 1.31 & 8.46 \\
\hline \multicolumn{8}{c}{ LOI = Loss On Ignition. }
\end{tabular}

The surface morphology of the adsorbent is presented in Figure 1 together with the electron dispense X-ray spectrum. The morphology of the RK clay appears rough spongier with some irregularly shaped agglomerates. After modification, the surface appears smoother with irregularly shaped agglomerates on top. Furthermore, the surface appears more porous which could be due to the expansion of clay interlayers during modification. Increased porosity could influence the diffusion of adsorbate into the adsorbent's particles leading to enhanced adsorption capacity. The Electron Dispersive X-ray Spectroscopy (EDS) spectrum of FMK confirmed the presence of Mn and Fe on the surface of the clay, which shows that the surface of the clay has been modified successfully. Qualitative EDS showed an increase in Fe content from 3.7 to $9.4 \%$, and Mn which was not detected on raw clay was found to be $2.27 \%$ in the modified clay.

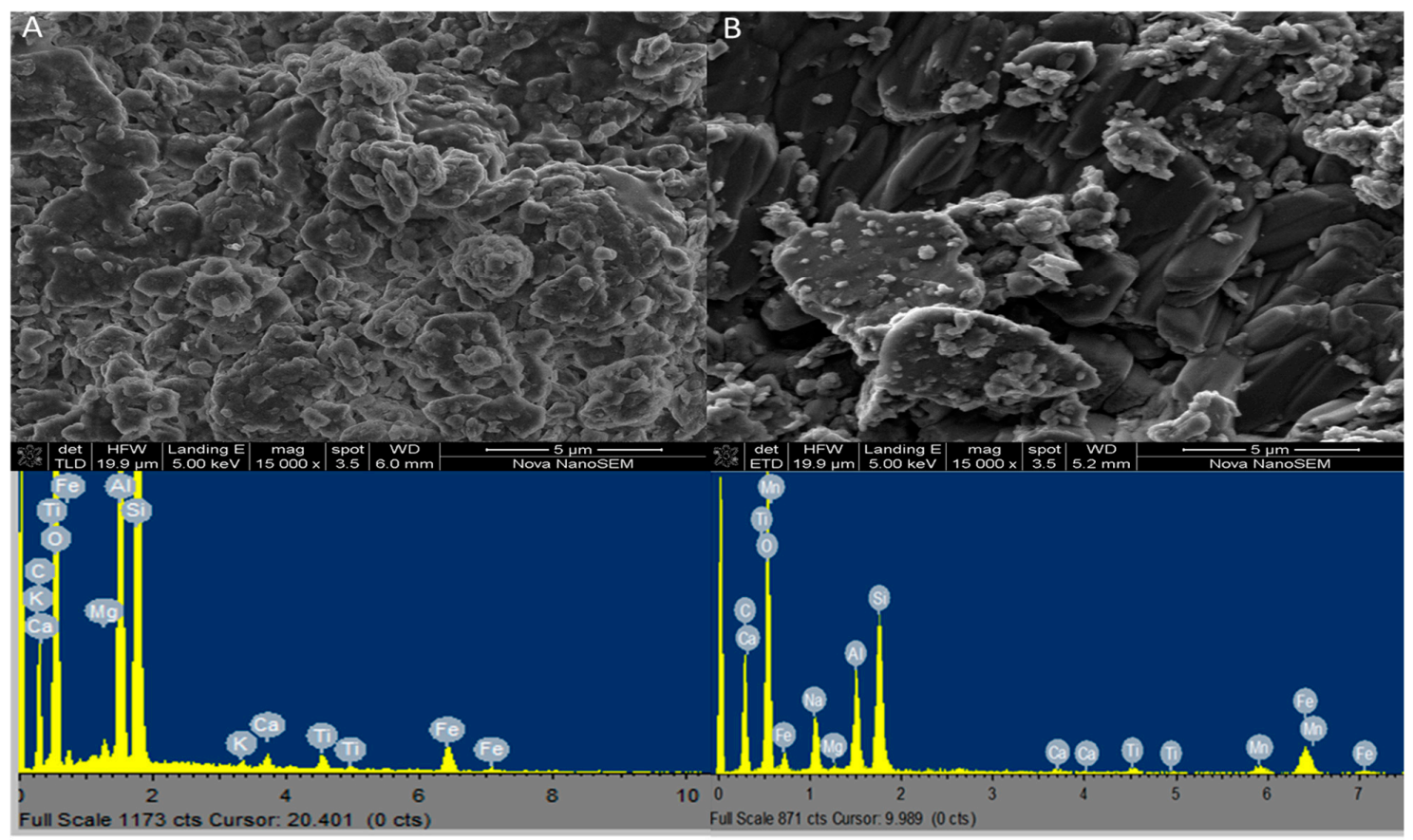

Figure 1. SEM Micrographs and EDS spectrums of raw kaolin (RK) and FMK.

The BET surface area analysis results showed an increase in the total surface area and pore volume from $19.02 \mathrm{~m}^{2} / \mathrm{g}$ to $29.8 \mathrm{~m}^{2} / \mathrm{g}$ and from 0.04 to $0.083 \mathrm{cc} / \mathrm{g}$, respectively (Table 2). This could be attributed to propping up of the parent clay mineral interlayer structure during modification. The pore diameter decreased from 9.54 to $8.5 \mathrm{~nm}$ after modification. The decrease in pore diameter could be an indication that the Fe and Mn oxides diffused into the pores of RK during modification. Based on the average pore diameter range, the clay can be classified as a mesoporous material. 
Table 2. Brunauer, Emmett, and Teller (BET) surface area, pore volume, and pore diameter of the raw kaolin (RK) and FMK.

\begin{tabular}{cccc}
\hline Clays & BET Surface Area $\left(\mathbf{m}^{2} / \mathbf{g}\right)$ & Pore Volume $(\mathrm{cc} / \mathrm{g})$ & Pore Diameter $(\mathbf{n m})$ \\
\hline RK & 19.02 & 0.04 & 9.54 \\
\hline FMK & 29.8 & 0.083 & 8.5 \\
\hline
\end{tabular}

\subsection{Batch Experiments}

\subsubsection{Effect of Contact Time and Adsorption Kinetics}

The effect of contact time on $\mathrm{As}(\mathrm{V})$ adsorption is depicted in Figure 2. It is clear that the adsorption capacity increases with increasing contact time. In order to gain more insight into the possible As(V) adsorption mechanisms together with the reaction pathways, three commonly used adsorption kinetics models, namely, pseudo-first-order model (PFO), pseudo-second-order reaction model (PSO), and the intra-particle diffusion model, were used [15]. The nonlinear equations of PFO and PSO are depicted by Equations (3) and (4), respectively, while the intra-particle diffusion model is depicted by Equation (5) [16]

$$
\begin{gathered}
\mathrm{q}_{\mathrm{t}}=\mathrm{q}_{\mathrm{e}}\left(1-\mathrm{e}^{-\mathrm{k}_{1} \mathrm{t}}\right) \\
\mathrm{q}_{\mathrm{t}}=\frac{\mathrm{q}_{\mathrm{e}}^{2} \mathrm{k}_{2} \mathrm{t}}{1+\mathrm{k}_{2} \mathrm{q}_{\mathrm{e}} \mathrm{t}} \\
\mathrm{q}_{\mathrm{t}}=\mathrm{k}_{\mathrm{i}} \mathrm{t}^{0.5}+\mathrm{C}
\end{gathered}
$$

where $\mathrm{q}_{\mathrm{e}}(\mathrm{mg} / \mathrm{g})$ and $\mathrm{q}_{\mathrm{t}}(\mathrm{mg} / \mathrm{g})$ represent the adsorption capacity at equilibrium and at time $\mathrm{t}(\mathrm{min})$, respectively. $\mathrm{K}_{1}\left(\mathrm{~min}^{-1}\right), \mathrm{K}_{2}(\mathrm{~g} / \mathrm{mg} \cdot \mathrm{min})$, and $\mathrm{K}_{\mathrm{i}}\left(\mathrm{mg} / \mathrm{g} \cdot \mathrm{min}^{-0.5}\right)$ are rate constants for PFO, PSO, and intra-particle diffusion model, respectively, and $\mathrm{C}$, intercept, is the constant associated to the thickness of the boundary layer. A higher value of $\mathrm{C}$ corresponds to the greater effect on the limiting boundary layer. The nonlinear plots for PFO and PSO are included in Figure 2, while the constant values are presented in Table 3. Based on the regression coefficient values, the data fitted better to PSO indicating that sorption of $\mathrm{As}(\mathrm{V})$ occurred via chemisorption. The intra-particle diffusion plot in Figure 3 shows that adsorption of $\mathrm{As}(\mathrm{V})$ onto FMK occur in three stages. First is associated to adsorption on the boundary layer of the adsorbent where $\mathrm{As}(\mathrm{V})$ ions are attracted to the surface of the adsorbent, and the second stage is attributed to intra-particle diffusion wherein $\mathrm{As}(\mathrm{V})$ ions are diffusing into the pores of the adsorbent. The third stage indicates equilibrium adsorption which involves the chemical interaction between $\mathrm{As}(\mathrm{V})$ and atoms within the particles. The intra-particle rate constant $\left(\mathrm{K}_{\mathrm{id}}\right)$ determined from the slope (Table 4) was higher at phase 1 indicating that adsorption at the boundary layer occurs much faster as compared to intra-particle diffusion and equilibrium adsorption. The value of $C$, the constant related to the thickness of the boundary layer, was found to be increasing from the first stage to third

\begin{tabular}{|c|c|c|c|c|c|c|}
\hline \multirow[b]{2}{*}{$q_{e} \exp (\mathrm{mg} / \mathrm{g})$} & \multicolumn{3}{|c|}{ Pseudo-First-Order } & \multicolumn{3}{|c|}{ Pseudo-Second-Order } \\
\hline & $K_{1}\left(\min ^{-1}\right)$ & $\mathrm{q}_{\text {e cal }}(\mathrm{mg} / \mathrm{g})$ & $\mathbf{R}^{2}$ & $K_{2}\left(\mathrm{mg} / \mathrm{g} \cdot \min ^{-1}\right)$ & $\mathrm{q}_{\mathrm{e} \text { cal }}(\mathrm{mg} / \mathrm{g})$ & $\mathbf{R}^{2}$ \\
\hline 5.36 & 0.011 & 1.42 & 0.89 & 0.05 & 5.49 & 0.99 \\
\hline
\end{tabular}
(Table 4), indicating the increase in the boundary layer of the adsorbent particles.

Table 3. Parameters for pseudo-first and second-order reaction kinetics model. 


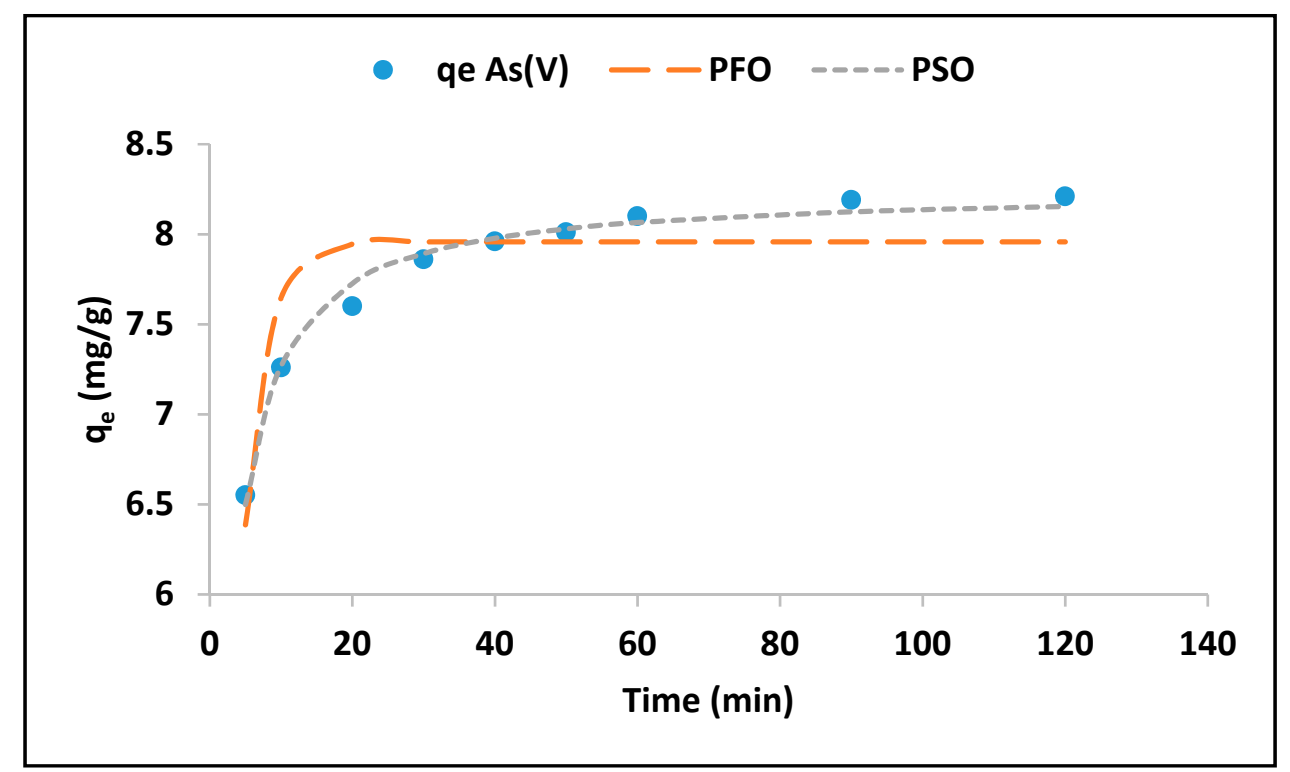

Figure 2. Effect of contact time on the adsorption of $\mathrm{As}(\mathrm{V})$ and adsorption kinetics.

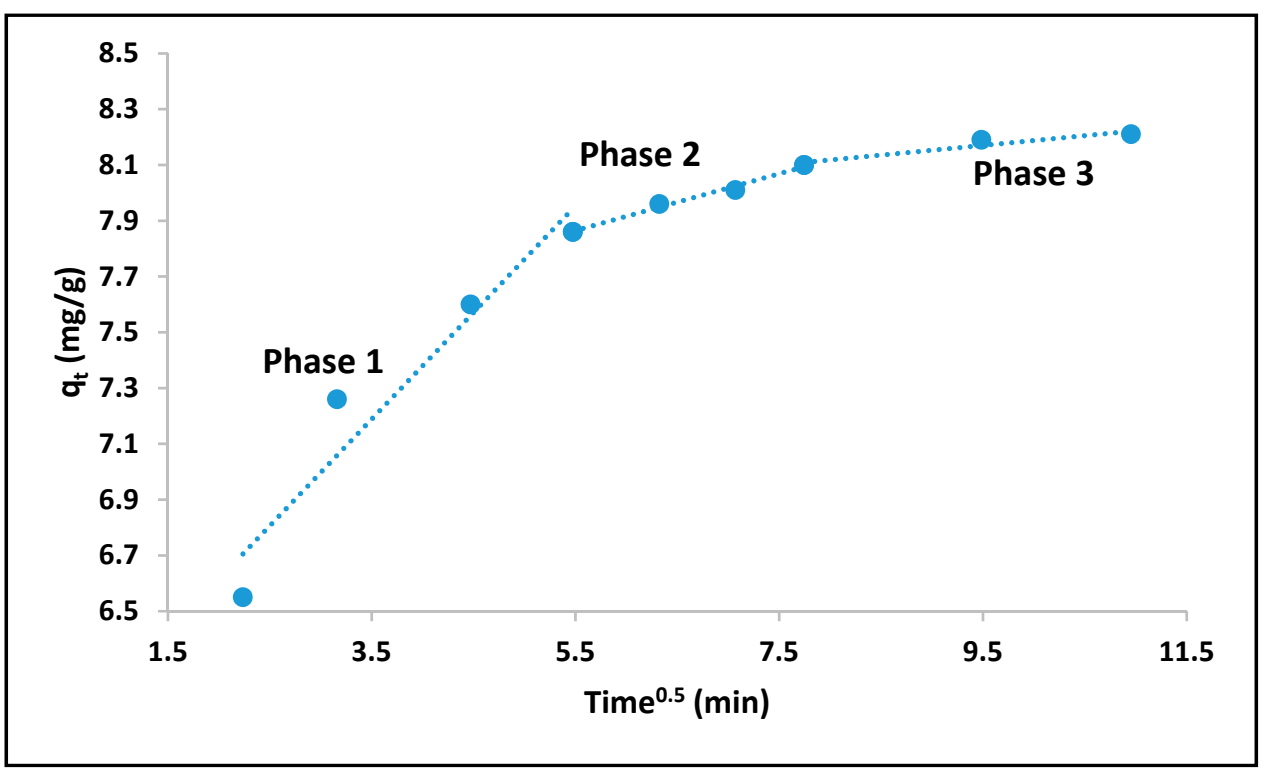

Figure 3. Intra-particle diffusion plot for $\mathrm{As}(\mathrm{V})$ adsorption onto FMK.

Table 4. Parameters for intra-particle diffusion model.

\begin{tabular}{cccccc}
\hline $\mathrm{K}_{\mathrm{id} \mathbf{1}}\left(\mathrm{mg} / \mathrm{g} \cdot \mathbf{~ m i n}^{\mathbf{1} / 2}\right)$ & $\mathrm{C}_{\mathbf{1}}$ & $\mathrm{K}_{\mathrm{id} \mathbf{2}}\left(\mathrm{mg} / \mathrm{g} \cdot \mathbf{~ m i n}^{\mathbf{1} / \mathbf{2}}\right)$ & $\mathrm{C}_{\mathbf{2}}$ & $\mathrm{K}_{\mathrm{id} 3}\left(\mathrm{mg} / \mathrm{g} \cdot \mathbf{m i n}^{\mathbf{1} / \mathbf{2}}\right)$ & $\mathrm{C}_{\mathbf{3}}$ \\
\hline 0.2 & 3.54 & 0.16 & 4.27 & 0.05 & 5.1 \\
\hline
\end{tabular}

\subsubsection{Effect of Adsorbate Concentration and Adsorption Isotherms}

The effect of adsorbate concentration and adsorption isotherms were evaluated by varying the initial $\mathrm{As}(\mathrm{V})$ concentration from 1 to $30 \mathrm{mg} / \mathrm{L}$. The experiment was done at 298, 308, and $323 \mathrm{~K}$. Figure 4 depicts the variation of adsorption capacity with equilibrium concentration. It was observed that the adsorption capacity increased with increasing equilibrium concentration. Furthermore, the adsorption capacity increased with increasing temperature. 


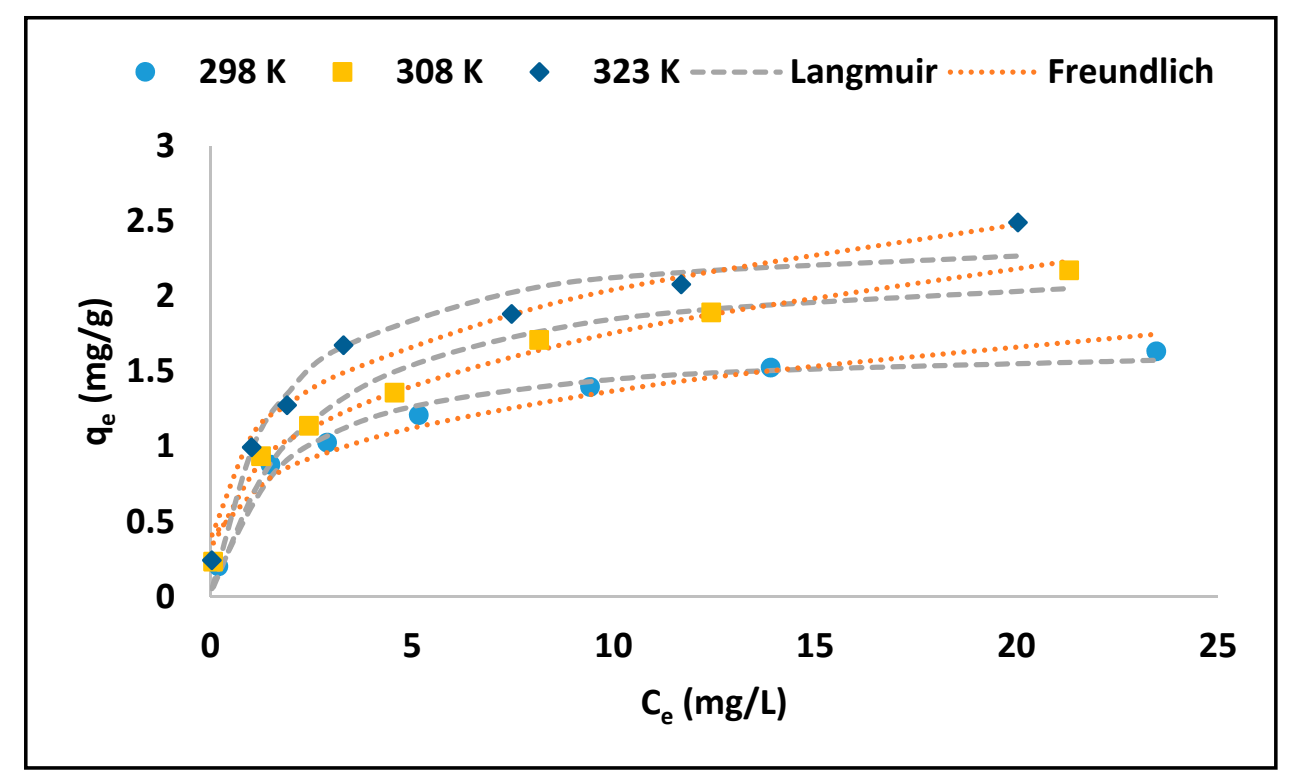

Figure 4. Adsorption isotherms for As(V) removal onto FMK.

The nonlinear Equations of Langmuir and Freundlich isotherm models (Equations (6) and (7), respectively) were used to describe the relationship between the adsorbate concentration and the amount of adsorbate adsorbed on the surface of the adsorbent $[17,18]$.

$$
\begin{gathered}
\mathrm{q}_{\mathrm{e}}=\frac{\mathrm{q}_{\max } \mathrm{K}_{\mathrm{L}} \mathrm{C}_{\mathrm{e}}}{1+\mathrm{K}_{\mathrm{L}} \mathrm{C}_{\mathrm{e}}} \\
\mathrm{q}_{\mathrm{e}}=\mathrm{K}_{\mathrm{f}} \mathrm{C}_{\mathrm{e}}^{1 / \mathrm{n}}
\end{gathered}
$$

where $C_{e}(\mathrm{mg} / \mathrm{L})$ is the $\mathrm{As}(\mathrm{V})$ concentration at equilibrium, $\mathrm{q}_{\mathrm{e}}(\mathrm{mg} / \mathrm{g})$ is the adsorption capacity at equilibrium, $Q_{\max }(\mathrm{mg} / \mathrm{g})$ is the maximum saturated monolayer adsorption capacity, $K_{L}(\mathrm{~L} / \mathrm{mg})$ is the constant related to the affinity between adsorbent and adsorbate, $K_{\mathrm{f}}(\mathrm{mg} / \mathrm{g})$ is the Freundlich constant related to adsorption capacity, and $\mathrm{n}$ is the Freundlich intensity parameter which indicates the magnitude of the adsorption driving force or the surface heterogeneity. The nonlinear plots are presented in Figure 4, while the model's parameters are presented in Table 5. The maximum adsorption capacity value achieved according to Langmuir was found to be correlating better with the experimental adsorption capacity as compared to the values observed from the Freundlich adsorption model. Furthermore, the correlation coefficient values for Langmuir at both temperatures was found to be close to unity and high compared to the ones achieved from the Freundlich model. As such, the adsorption data for $\mathrm{As}(\mathrm{V})$ by FMK is described by the Langmuir model. This suggests that adsorption occurred on a monolayer surface wherein, during adsorption, there was no interaction between the adsorbate molecules. Furthermore, the surface of the material is homogeneous. This can be supported by SEM images, which showed that the surface of the material has some flat plate-like micro-structures of the same size. For the data described by the Langmuir isotherm model, it is essential to calculate the separation factor/equilibrium dimensionless parameter, $R_{L}$ [16]. The $R_{L}$ is calculated using Equation (8) below.

$$
\mathrm{R}_{\mathrm{L}}=\frac{1}{1+\mathrm{K}_{\mathrm{L}} \mathrm{C}}
$$

If $R_{L}=0$, adsorption is irreversible; $R_{L}>1$, adsorption is unfavorable; $R_{L}=1$, adsorption is reversible; $R_{L}<1$, adsorption is favorable. It is noted in Table 5 that $R_{L}$ values for $A s(V)$ at both temperatures are within the range of $0-1$, which indicates that adsorption of $\mathrm{As}(\mathrm{V})$ by FMK was favorable. This was further confirmed by the $1 / n$ values for Freundlich constant related to adsorption intensity, which also ranges between zero and one. 
Table 5. Constant parameters for Langmuir and Freundlich adsorption isotherm model.

\begin{tabular}{cccccccc}
\hline & \multicolumn{3}{c}{ Langmuir } & \multicolumn{3}{c}{ Freundlich } \\
\cline { 2 - 8 } & $\mathbf{q}_{\mathbf{m}} \mathbf{( m g / g )}$ & $\mathbf{K}_{\mathbf{L}}(\mathbf{L} / \mathbf{m g})$ & $\mathbf{R}^{\mathbf{2}}$ & $\mathbf{R}_{\mathbf{L}}$ & $\mathbf{K}_{\mathbf{f}}(\mathbf{m g} / \mathbf{g})$ & $\mathbf{1 / n}$ & $\mathbf{R}^{\mathbf{2}}$ \\
\hline $298 \mathrm{~K}$ & 1.67 & 0.54 & 0.98 & $0.62-0.05$ & 0.7 & 0.28 & 0.91 \\
$308 \mathrm{~K}$ & 2.08 & 0.62 & 0.97 & $0.64-0.05$ & 0.85 & 0.32 & 0.95 \\
$323 \mathrm{~K}$ & 2.44 & 0.64 & 0.97 & $0.60-0.04$ & 1.08 & 0.32 & 0.96 \\
\hline
\end{tabular}

\subsubsection{Adsorption Thermodynamics}

Adsorption thermodynamics studies were conducted using the isotherm data obtained at different temperatures in order to elucidate the adsorption mechanisms. Equations (9) and (10) were used to determine the adsorption thermodynamics parameters, such as Gibbs free energy change $\left(\Delta G^{\circ}\right)$, enthalpy of change $\left(\Delta \mathrm{H}^{\circ}\right)$, and the entropy of change $\left(\Delta \mathrm{S}^{\circ}\right)[19]$.

$$
\begin{gathered}
\Delta \mathrm{G}^{\circ}=-\mathrm{RT} \ln \mathrm{K}_{\mathrm{c}}=-\mathrm{RT} \ln \mathrm{K}_{\mathrm{c}} \\
\ln \mathrm{K}_{\mathrm{L}}=-\frac{\Delta \mathrm{H}^{\circ}}{\mathrm{RT}}+\frac{\Delta \mathrm{S}^{\circ}}{\mathrm{R}}
\end{gathered}
$$

where $\mathrm{R}$ is the molar gas constant, $8.314 \mathrm{~J} \mathrm{~mol}^{-1} \mathrm{~K}^{-1}, \mathrm{~T}$ is the absolute temperature in Kelvin, $\Delta \mathrm{G}^{\circ}$ $(\mathrm{KJ} / \mathrm{mol})$ is the Gibbs free energy change. $\Delta \mathrm{H}^{\circ}(\mathrm{J} / \mathrm{mol})$ is enthalpy change, $\Delta S^{\circ}(\mathrm{J} / \mathrm{mol})$ is the change in entropy, and $\mathrm{K}_{\mathrm{c}}$ is the dimensionless parameter derived from the value of Langmuir adsorption isotherm $(\mathrm{L} / \mathrm{mg})$ by multiplying $\mathrm{L} / \mathrm{mg}$ with $74.921 \times 10^{3}$. Values $\Delta \mathrm{H}$ and $\Delta \mathrm{S}$ are determined from the slope and intercept of a plot of $1 n K_{C}$ against $1 / \mathrm{T}$ (Figure 5). Thermodynamic parameters are presented in Table 6. The value $\Delta \mathrm{G}^{\circ}$ was found to be negative indicating that adsorption of $\mathrm{As}(\mathrm{V})$ onto FMK was spontaneous and favorable. The value for the enthalpy of change, $\Delta \mathrm{H}^{\circ}$, was positive for $\mathrm{As}(\mathrm{V})$. This suggests that adsorption of $\mathrm{As}(\mathrm{V})$ was endothermic and a chemisorption process. The value of $\Delta \mathrm{S}^{\circ}$ was found to be positive, indicating $\mathrm{As}(\mathrm{V})$ ions were randomly distributed on the surface of the adsorbent.

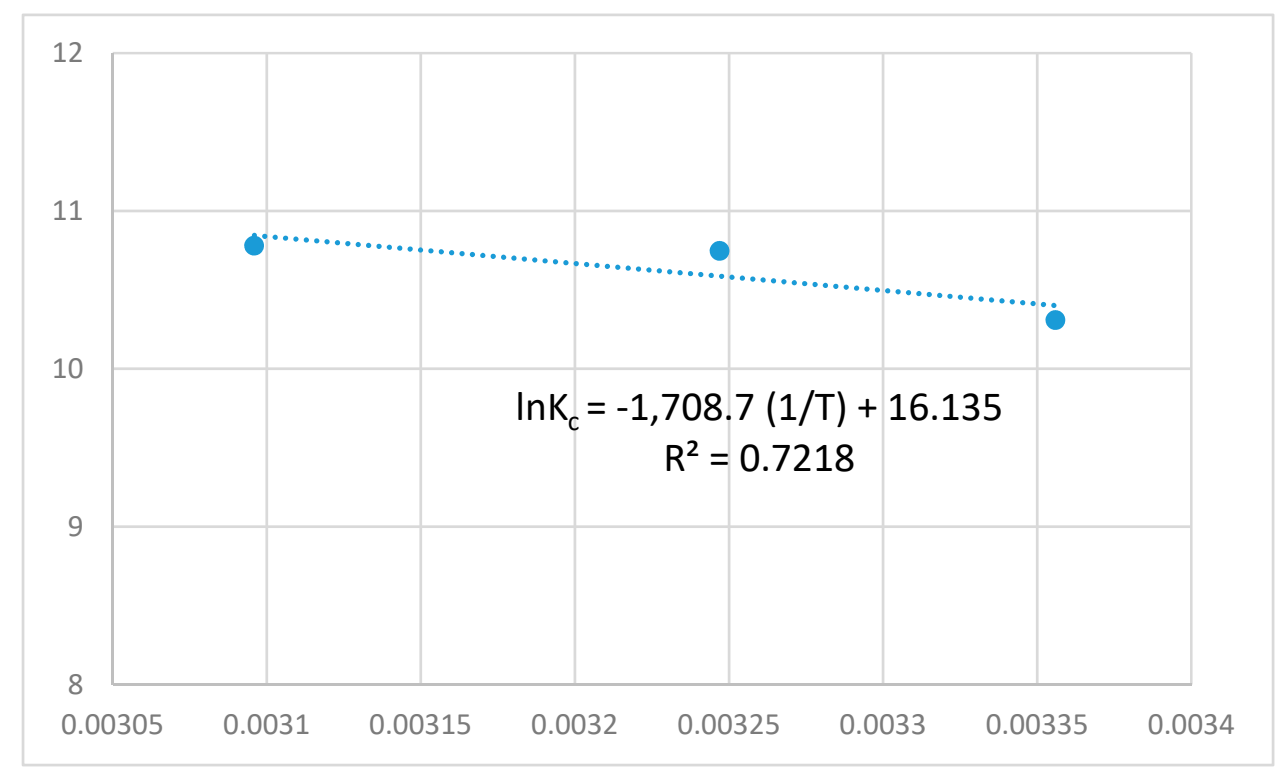

Figure $5 . \ln \mathrm{K}_{\mathrm{c}}$ as a function of reciprocal of adsorption temperature. 
Table 6. Thermodynamics parameters for As(V) adsorption onto FMK.

\begin{tabular}{ccc}
\hline$\Delta \mathrm{G}^{\circ}(\mathrm{KJ} / \mathbf{m o l})$ & $\Delta \mathbf{H}^{\circ}(\mathrm{KJ} / \mathbf{m o l})$ & $\Delta \mathbf{S}^{\circ}(\mathrm{J} / \mathbf{m o l})$ \\
\hline $298 \mathrm{~K}=-25.54$ & & \\
$303 \mathrm{~K}=-27.12$ & 14.2 & 134.1 \\
$323 \mathrm{~K}=-28.94$ & & \\
\hline
\end{tabular}

\subsubsection{Effect of Solution $\mathrm{pH}$}

The effect of $\mathrm{pH}$ onto $\mathrm{As}(\mathrm{V})$ removal is presented in Figure 6. It is noted that the percentage of $\mathrm{As}(\mathrm{V})$ removal by FMK decreases with increasing $\mathrm{pH}$. At acidic and alkaline $\mathrm{pH}$ ranges, $\mathrm{As}(\mathrm{V})$ exist as $\mathrm{H}_{2} \mathrm{AsO}_{4}{ }^{-}, \mathrm{HAsO}_{4}{ }^{2-}$, and $\mathrm{AsO}_{4}{ }^{3-}$ [20]. Therefore, at acidic $\mathrm{pH}$, where the surface of the adsorbent is positively charged, adsorption occurs via electrostatic attraction (Equation (11)). As the $\mathrm{pH}$ increases, the surface becomes negatively charged. This promotes electrostatic repulsion between $\mathrm{As}(\mathrm{V})$ ions and the surface charges and hence the decrease in the percentage of removal. Ion exchange and surface complexation could be the removal mechanisms at these $\mathrm{pH}$ ranges. Equations (12) and (13) represent the neutral to alkaline $\mathrm{pH}$ level, respectively.

$$
\begin{gathered}
\equiv \mathrm{MOH}^{+}+\mathrm{H}_{2} \mathrm{AsO}_{4}^{-} \rightarrow \mathrm{MOHAsO}_{4}+2 \mathrm{H}^{+} \\
\equiv \mathrm{MOH}+\mathrm{HAsO}_{4}^{-} \leftrightarrow \equiv \mathrm{MHAsO}_{4}^{-}+\mathrm{H}_{2} \mathrm{O} \\
\equiv \mathrm{MOH}+\mathrm{HAs}_{4}^{2-} \leftrightarrow \equiv \mathrm{MAs}_{4}^{2-}+\mathrm{H}_{2} \mathrm{O}
\end{gathered}
$$

where $\mathrm{M}$ represents metals on the surface of the adsorbent.

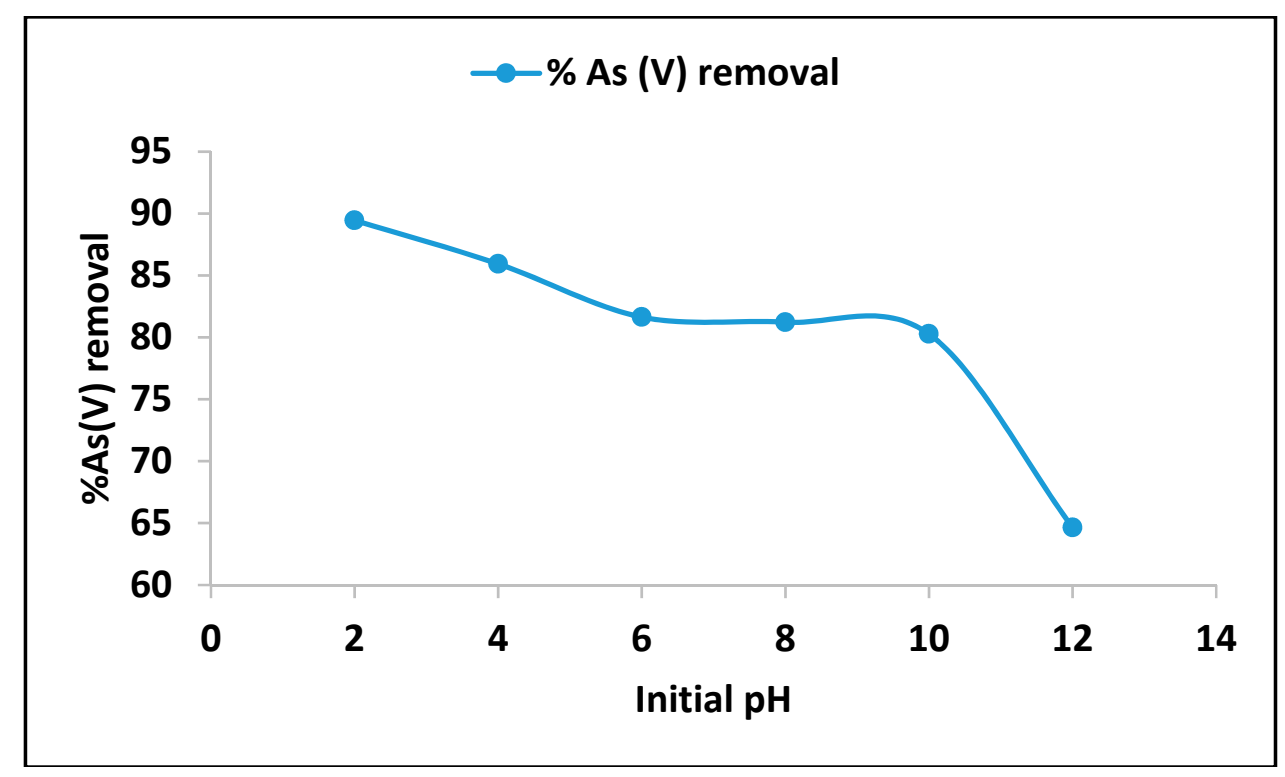

Figure 6. The effect of initial $\mathrm{pH}$ on $\mathrm{As}(\mathrm{V})$ removal onto FMK (Initial As(V) concentration $5 \mathrm{mg} / \mathrm{L}$, $0.4 \mathrm{~g} / 100 \mathrm{~mL}$ adsorbent dosage, $60 \mathrm{~min}$ contact time at $250 \mathrm{rpm}$ shaking speed).

\subsubsection{Effect of Co-Existing Anions}

The effect of co-existing anions is depicted in Figure 7. It is observed that the percentage of $\mathrm{As}(\mathrm{V})$ removal decreased from 95.33 to $91.11 \%$ in the presence of sulfates. Furthermore, the percentage of $\mathrm{As}(\mathrm{V})$ removal decreased to $94.88 \%$ in the presence of chloride and nitrates, respectively. The presence of fluoride and carbonates showed no inhibition towards $\mathrm{As}(\mathrm{V})$ removal. The decrease in percentage could be due to competition for adsorption sites between $\mathrm{As}(\mathrm{V})$ ions and other co-existing anions. It is, 
however, noted that the adsorption of both $\mathrm{As}(\mathrm{V})$ was still above $90 \%$ despite the presence of other co-existing anions.

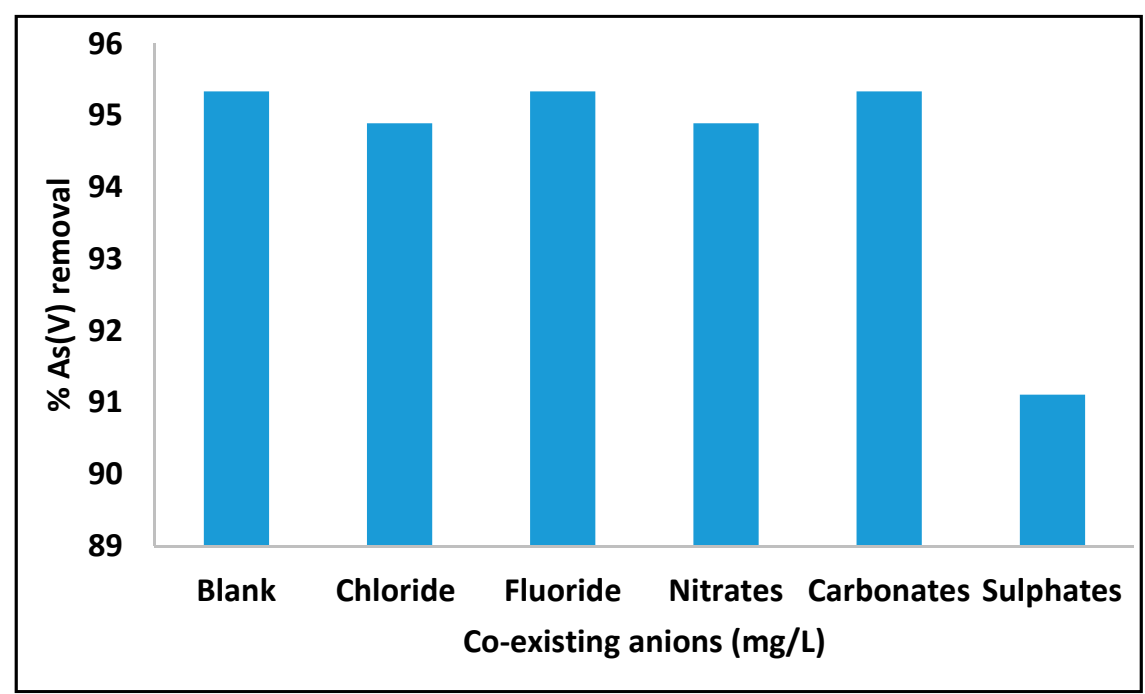

Figure 7. Effects of co-existing anions in $\mathrm{As}(\mathrm{V})$ removal by FMK $(5 \mathrm{mg} / \mathrm{L} \mathrm{As}(\mathrm{V})$ initial concentration, $5 \mathrm{mg} / \mathrm{L}$ of each co-existing ions, $0.4 \mathrm{~g} / 100 \mathrm{~mL}$ adsorbent dosage, 6.7 initial $\mathrm{pH}$, and $60 \mathrm{~min}$ agitation time at $250 \mathrm{rpm})$.

\subsubsection{Adsorbent Regeneration and Reusability}

The reusability of the adsorbent was conducted for up to six cycles using $0.1 \mathrm{M} \mathrm{K}_{2} \mathrm{SO}_{4}$ as a regenerating solution, and the results are presented in Figure 8. It is observed that the percentage of $\mathrm{As}(\mathrm{V})$ removal slightly increased from 94.5 to $95.8 \%$ in the first reuse cycle. The slight increase could be suggesting that there were more sorption sites activated after treatment by $\mathrm{K}_{2} \mathrm{SO}_{4}$. Thereafter, the percentage of $\mathrm{As}(\mathrm{V})$ removal decreased continuously with increasing regeneration-reuse cycles. The decrease in percentage removal could be due to inadequate reactivation of the adsorption sites. However, it is interesting to note that adsorption remained beyond $85 \%$ even at the sixth cycle. This result indicates that FMK is a sustainable adsorbent for use in arsenic removal since it can be regenerated easily.

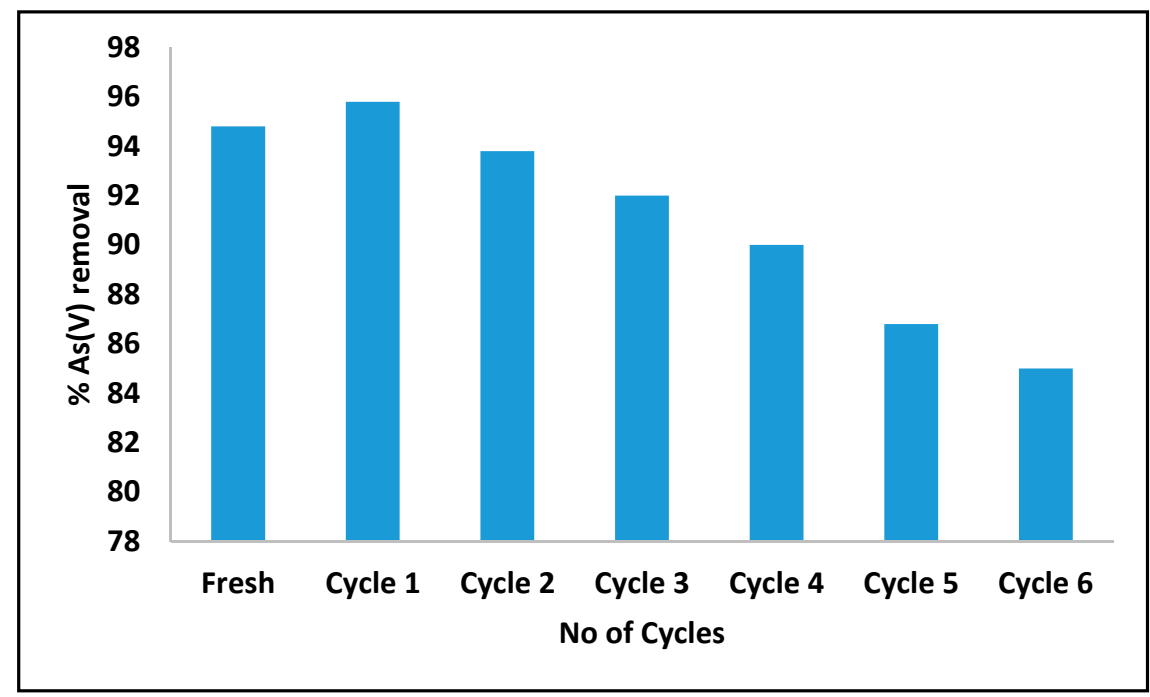

Figure 8. The variation of $\mathrm{As}(\mathrm{V})$ removal by $\mathrm{FMK}$ as a function of regeneration cycles $(5 \mathrm{mg} / \mathrm{L} \mathrm{As}(\mathrm{V})$, $0.4 \mathrm{~g} / 100 \mathrm{~mL}$ adsorbent dosage, $60 \mathrm{~min}$ contact time at $250 \mathrm{rpm}$ shaking speed). 


\subsubsection{Comparison with Other Adsorbents}

The comparison of adsorption capacities between FMK and other adsorbents reported in the literature is presented in Table 7. It is noted that FMK showed higher adsorption capacity compared to raw kaolin clay soils and lateritic soils. However, its adsorption capacity was lower compared to other iron oxides-based adsorbent at specified conditions. The adsorption capacity depends on the adsorbate concentration and the adsorbent dosage used in the experiment. The higher the initial adsorbate concentration, the higher the adsorption capacity. The efficiency of FMK was further evaluated by testing a solution containing $50 \mu \mathrm{g} / \mathrm{L}$ using an adsorbent dosage of $0.4 \mathrm{~g} / 100 \mathrm{~mL}$, and the final concentration of $7.88 \mu \mathrm{g} / \mathrm{L}$ was recorded which corresponds to the adsorption capacity of $10.53 \mu \mathrm{g} / \mathrm{g}$. This affirms that FMK synthesized in this study is suitable for use in arsenic remediation since it has the potential to reduce the concentration to a permissible guideline value for drinking water $(10 \mu \mathrm{g} / \mathrm{L})$.

Table 7. Comparison with other adsorbents.

\begin{tabular}{|c|c|c|c|}
\hline Adsorbent & Experimental Conditions & As(V) Adsorption Capacity & References \\
\hline Raw kaolin clay soils & $\begin{array}{l}\text { Adsorbate concentration: } 1-15 \mathrm{mg} / \mathrm{L} ; \\
\text { adsorbent dosage: } 0.7 \mathrm{~g} / 100 \mathrm{~mL}\end{array}$ & $1.08 \mathrm{mg} / \mathrm{g}$ & Mudzielwana et al. [6] \\
\hline FeOOH modified clay & $\begin{array}{l}\text { Adsorbate concentration: } 5-400 \mathrm{mg} / \mathrm{g} \text {; } \\
\text { adsorbent dosage: } 0.5 \mathrm{~g} / 40 \mathrm{~mL} \text {. }\end{array}$ & $15.62 \mathrm{mg} / \mathrm{g}$ & Ozola et al. [12] \\
\hline Lateritic soils & $\begin{array}{l}\text { Adsorbate concentration: } 0.01-30 \mathrm{mg} / \mathrm{L} \text {; } \\
\text { adsorbate dosage: } 1 \mathrm{~g} / 100 \mathrm{~mL}\end{array}$ & $2.0 \mathrm{mg} / \mathrm{g}$ & Boglione et al. [21] \\
\hline $\mathrm{FeOOH} / \mathrm{Al}_{2} \mathrm{O}_{3}$ granules & $\begin{array}{l}\text { Adsorbate concentration: } 10-100 \mathrm{mg} / \mathrm{L} \text {; } \\
\text { Adsorbent dosage: } 1.10 \mathrm{~g} / 220 \mathrm{~mL}\end{array}$ & $3.451 \mathrm{mg} / \mathrm{g}$ & Wang et al. [22] \\
\hline FMK & $\begin{array}{l}\text { Adsorbate concentration: } 1-30 \mathrm{mg} / \mathrm{L} \text {; } \\
\text { adsorbent dosage: } 0.4 \mathrm{~g} / 100 \mathrm{~mL}\end{array}$ & $2.44 \mathrm{mg} / \mathrm{g}$ & Present study \\
\hline
\end{tabular}

\section{Conclusions}

Fe-Mn bimetal modified kaolin clay has the potential for use in the uptake of arsenic from the solution. The adsorption kinetics data showed that adsorption of $\mathrm{As}(\mathrm{V})$ by FMK occurred via chemisorption, and it is a complex process that involves both boundary layer, diffusion, and equilibrium adsorption. Adsorption isotherm data fitted better to the Langmuir isotherm model, indicating that adsorption occurred on a monolayer surface and there is no interaction between the adsorbate molecules. The thermodynamics studies showed that the process occurred spontaneously, and $\mathrm{As}(\mathrm{V})$ ions were randomly distributed on the surface of the adsorbent. The effect of $\mathrm{pH}$ showed that the adsorption was optimum at acidic $\mathrm{pH}$ level. The effect of co-existing anions showed that the presence of $\mathrm{SO}_{4}{ }^{2-}, \mathrm{Cl}^{-}$, and $\mathrm{NO}_{3}{ }^{-}$inhibited $\mathrm{As}(\mathrm{V})$ removal, while $\mathrm{F}^{-}$and $\mathrm{CO}_{3}{ }^{2-}$ showed no effect on the adsorption of $\mathrm{As}(\mathrm{V})$. Regeneration study showed that FMK could be regenerated and reused effectively for up to six times. This study recommended that FMK synthesized in this study could be used for arsenic remediation.

Author Contributions: Conceptualization, W.M.G. and R.M.; Methodology, R.M.; Validation, R.M., M.W.G. and P.N.; Formal Analysis, R.M.; Resources, M.W.G.; Writing-Original Draft Preparation, R.M.; Writing-Review \& Editing, M.W.G. and P.N.; Supervision, M.W.G. and P.N.; Project Administration, R.M.; Funding Acquisition, M.W.G.

Funding: This research was funded by University of Venda RPC grant number SES/17/ERM/03 and Prof Gitari's DHET Research Incentives (Cost Centre-P118).

Acknowledgments: We would like to acknowledge the student financial support from Sasol Inzalo Foundation-NRF South Africa.

Conflicts of Interest: The authors declare no conflict of interest.

\section{References}

1. Bretzler, A.; Lalanne, F.; Nikiema, J.; Podgorski, J.; Pfanninnger, M.; Berg, M.; Schirmer, M. Groundwater arsenic contamination in Burkina Faso, West Africa: Predicting and verifying regions at risk. Sci. Total Environ. 2017, 584-585, 958-970. [CrossRef] [PubMed] 
2. Minatel, B.C.; Sage, A.P.; Anderson, C.; Hubaux, R.; Marshall, E.M.; Lam, W.L.; Martinez, V.D. Environmental arsenic exposure: From genetic susceptibility to pathogenesis. Environ. Int. 2018, 112, 183-197. [CrossRef] [PubMed]

3. Rahman, M.A.; Rahman, A.; Khan, Z.K.; Renzaho, A.M.N. Human health risks and socio-economic perspectives of arsenic exposure in Bangladesh: A scoping review. Ecotoxicol. Eviron. Saf. 2018, 150, 335-343. [CrossRef] [PubMed]

4. Sarkar, A.; Paul, B. The global menace of arsenic and its convectional remediation-A critical review. Chemosphere 2016, 158, 37-49. [CrossRef] [PubMed]

5. World Health Organization (WHO). Guidelines for Drinking-Water Quality: Fourth Edition Incorporating the First Addendum; World Health Organization (WHO): Geneva, Switzerland, 2017.

6. Mudzielwana, R.; Gitari, W.M.; Ndungu, P. Evaluation of the adsorptive properties of locally available alumino-silicate clay in $\mathrm{As}(\mathrm{III})$ and $\mathrm{As}(\mathrm{V})$ remediation from groundwater. Phys. Chem. Earth Part A/B/C 2018. [CrossRef]

7. Zhang, W.; Liu, C.; Wang, L.; Zheng, T.; Ren, G.; Li, J.; Ma, J.; Zhang, Z.; Song, H.; Zhang, Z.; et al. A novel nanostructured Fe-Ti-Mn composite oxide doe highly efficient arsenic removal: Preparation and performance evaluation. Colloids Surf. A 2019, 561, 364-372. [CrossRef]

8. Saleh, T.A.; Sari, A.; Tuzen, M. Chitosan-modified vermiculite for As(III) adsorption from aqueous solution: Equilibrium, thermodynamic and kinetic studies. J. Mol. Liq. 2016, 937-945. [CrossRef]

9. Jeon, E.K.; Ryu, S.; Park, S.W.; Wang, L.; Tsang, D.C.W.; Baek, K. Enhanced adsorption of arsenic onto alum sludge modified by calcination. J. Clean. Prod. 2018, 176, 54-62. [CrossRef]

10. Zhang, G.; Liu, H.; Qu, J.; Jefferson, W. Arsenate uptake and arsenite simultaneous sorption and oxidation by Fe-Mn binary oxides: Influence of $\mathrm{Mn} / \mathrm{Fe}$ ratio, $\mathrm{pH}, \mathrm{Ca}^{2+}$, and humic acid. J. Colloid Interface. Sci. 2012, 366, 141-146. [CrossRef]

11. Uddin, K.F. A review on the adsorption of heavy metals by clay minerals, with special focus on the past decade. Chem. Eng. J. 2017, 308, 438-462. [CrossRef]

12. Ozola, R.; Krauklis, A.; Leitietis, M.; Burlakovs, J.; Vircava, I.; Bertina, L.A.; Bhatnager, A.; Klavin, M. FeOOH-modified clay sorbents for arsenic removal from aqueous solutions. Environ. Technol. Innov. 2019, 13, 364-372. [CrossRef]

13. Ren, X.; Zhang, Z.; Luo, H.; Dang, Z.; Yang, C.; Li, L. Adsorption of arsenic on modified montomorillonite. Appl. Clay Sci. 2014, 17-98, 17-23. [CrossRef]

14. Lalhamunsiama; Pawar, R.R.; Hong, S.M.; Jin, K.J.; Lee, S.M. Iron-oxide modified sericite alginate beads: A sustainable adsorbent for the removal of $\mathrm{As}(\mathrm{V})$ and $\mathrm{Pb}(\mathrm{II})$ from aqueous solutions. J. Mol. Liq. 2017, 240, 497-503. [CrossRef]

15. Gupta, S.S.; Bhattacharyya, K.G. Kinetics of adsorption of metal ions on inorganic materials: A review. Adv. Colloid. Interface Sci. 2011, 162, 39-58. [CrossRef] [PubMed]

16. Tran, H.N.; You, S.J.; Bendegharaie, A.H.; Chao, H.P. Mistakes and inconsistencies regarding adsorption of contaminants from aqueous solutions: A critical review. Water Res. 2017, 120, 88-116. [CrossRef] [PubMed]

17. Thakre, D.; Rayalu, S.; Kawade, R.; Meshram, S.; Subrt, J.; Labhsetwar, N. Magnesium incorporated bentonite clay for defluoridation of drinking water. J. Hazard. Mater. 2010, 180, 122-130. [CrossRef] [PubMed]

18. Maity, J.P.; Hsu, C.M.; Lee, W.C.; Bhattacharyya, P.; Bundschuh, J.; Chen, C.Y. Removal of fluoride from water through bacterial-surfactin mediated novel hydroxyapatite nanoparticle and its efficiency assessment: Adsorption isotherm, adsorption kinetic and adsorption Thermodynamics. Environ. Nanotechnol. Monit. Manag. 2018, 9, 18-28. [CrossRef]

19. Lin, L.; Qui, W.; Wang, D.; Huang, Q.; Song, Z.; Chaud, H.W. Arsenic removal in aquous solutions by novel Fe-Mn modified biochar composite: Characterization and mechanisms. Ecotoxicol. Environ. Saf. 2017, 514-521. [CrossRef]

20. Lee, S.M.; Lalhmunsiama; Thanhmingliana; Tiwari, D. Porous hybrid materials in the remediation of water contaminated with As(III) and As(V). Chem. Eng. J. 2015, 270, 496-507. [CrossRef] 
21. Boglione, R.; Griffa, C.; Panigatti, M.C.; Keller, S.; Schierano, M.C.; Asforno, M. Arsenic adsorption by soil from Misiones Province, Argenita. Environ. Technol. Innov. 2019, 13, 30-36. [CrossRef]

22. Wang, Z.; Shen, X.; Jing, M.; Li, C. Enhanced arsenic removal from drinking water by $\mathrm{FeOOH} /-\mathrm{Al}_{2} \mathrm{O}_{3}$ granules. J. Alloys Compd. 2018, 735, 1620-1628. [CrossRef]

(C) 2019 by the authors. Licensee MDPI, Basel, Switzerland. This article is an open access article distributed under the terms and conditions of the Creative Commons Attribution (CC BY) license (http://creativecommons.org/licenses/by/4.0/). 